
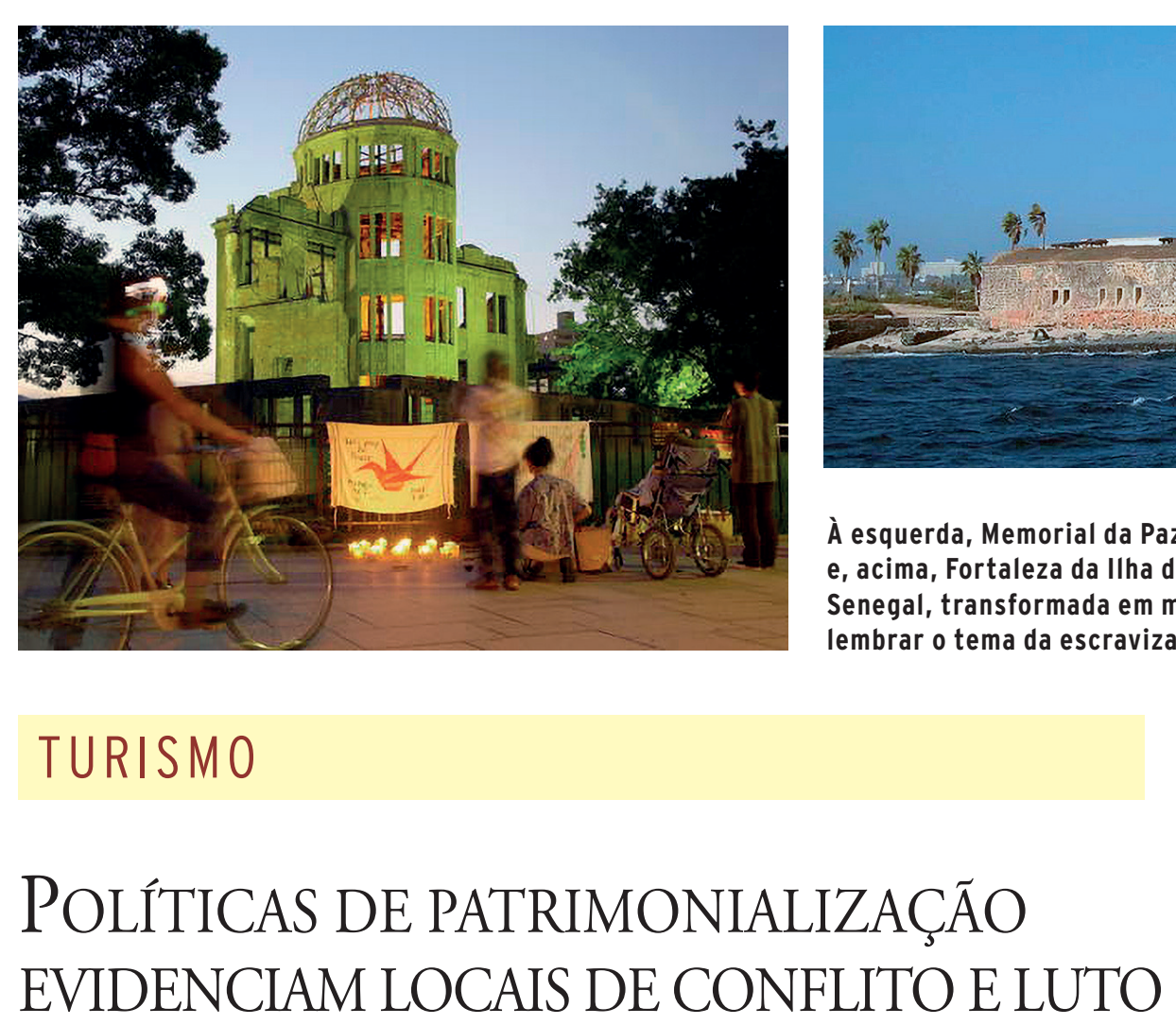

\title{
POLÍTICAS DE PATRIMONIALIZAÇÃO EVIDENCIAM LOCAIS DE CONFLITO E LUTO
}

Ilha de Gorée, no Senegal, o maior centro de tráfico de negros escravizados da costa africana. Auschwitz, na Polônia, uma rede de campos de concentração e extermínio. Hiroshima, no Japão, local que foi o epicentro da explosão de uma bomba atômica. Ilha Robben, na África do Sul, onde Nelson Mandela ficou prisioneiro por mais de duas décadas. O que esses locais têm em comum? Além de serem lugares marcados por uma história difícil, todos estão listados pela Organização das Nações Unidas para a Educação, a Ciência e a Cultura (Unesco) como patrimônio mundial, e recebem anualmente milhares de visitantes. $\mathrm{O}$ turismo em locais de memória difícil ou de conflito - também conhecido genericamente como "dark tourism" (do inglês "turismo som- brio”) não é uma prática recente. A Unesco adota políticas de patrimonialização desses locais desde a década de 1970. Porém, a discussão sobre esse tipo de turismo continua em alta. Além disso, se fora do Brasil esse turismo não é novidade, por aqui as políticas para transformar esses locais marcados por conflitos e luto em destino turístico ainda estão engatinhando. "Embora o Brasil tenha muitos locais que possam ser considerados memoriais ou que remetam a passados difíceis ou traumáticos, transformar a visitação a esses lugares em turismo não é uma prática corrente", explica a historiadora Cristina Meneguello, professorado Instituto de Filosofia eCiências Humanas (IFCH) da Universidade Estadual de Campinas (Unicamp). "Na verdade, são dois movimentos distintos: o primeiro é perceber que esses locais podem ser patrimonializados e auxiliar as futuras gerações a reconhecer momentos condenáveis da história nacional para evitar que aconteçam novamente - o Brasil já caminhou bastante nesses processos, principalmente na última década, nesse sentido. O segundo é 'turistificar' esses lugares, torná-los visitáveis, interessantes, apelando a sentimentos de medo ou empatia das pessoas. Esse tipo de 'turismo do medo' não é muito comum entre nós, e acho muito bom que não seja mesmo. Entre a conscientização e o desrespeito, é um passo muito pequeno, o que não nos beneficia em nada”, acredita Meneguello.

No Brasil, recentemente, ocorreram os processos de tombamento de instituições de profilaxia da hanseníase (os conhecidos "leprosários"), criadas especialmente nas décadas de 1930 e 1940. Símbolos de políticas segregacionistas, a patrimonialização desses locais permite um olhar diferenciado sobre a história do tratamento desses pacientes e convidam a refletir sobre a luta 


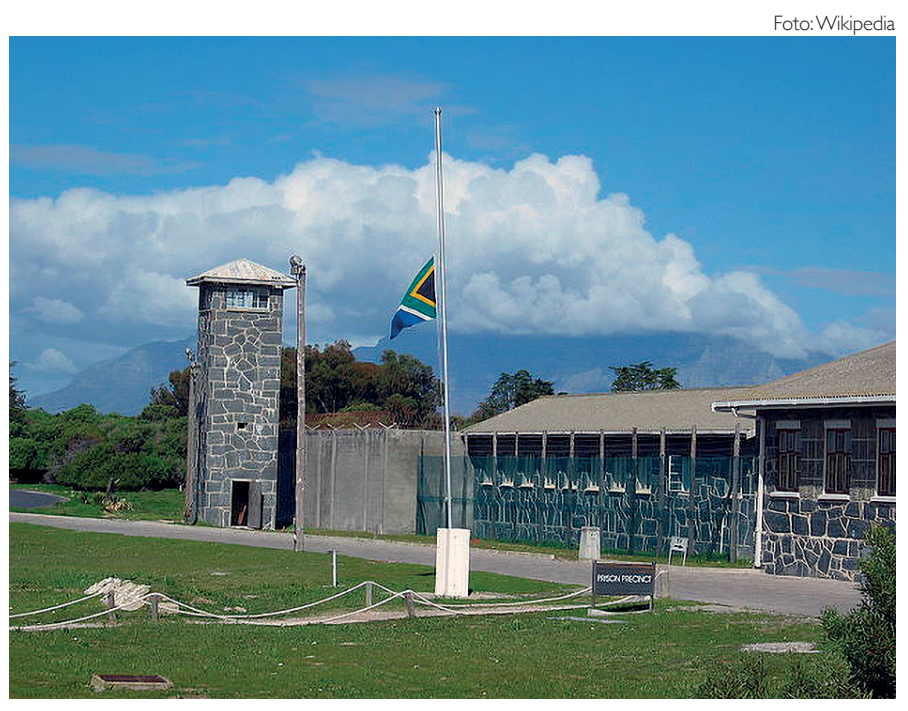

Local onde

Nelson Mandela

ficou preso, considerado patrimônio da humanidade pelaUnesco

dos portadores de hanseníase pelo reconhecimento de seus direitos à reparação pela forma como foram apartados da sociedade durante décadas. Essa rede de instituiçóes para o tratamento da hanseníase passou pelo processo de patrimonialização do Conselho de Defesa do Patrimônio Histórico Arqueológico, Artístico e Turístico (Condephaat), que tombou o asilo Complexo Padre Bento, antigo Sanatório Padre Bento (1931), em Guarulhos, e o antigo asilo Colônia Aimorés (1933), atual Instituto Lauro de Souza Lima, em Bauru. Além desses, o Condephaat também está estudando o tombamento de várias outras instituições.

DIFÍCIL DE LEMBRAR O Brasil possui vários locais que podem ser considerados de "conflito" ou de "luto". Os dois exemplos mais conhecidos são o Memorial da Resistência, na cidade de São Paulo, e o Sítio Arqueológico do Cais do Valongo, no Rio de Janeiro (RJ). O Memorial da Resistência se localiza na Estação Pinacoteca e hoje é um local destinado à preservação das memórias da resistência e da repressão política do país. Entre 1940 e 1983, o edifício, que hoje abriga o museu, foi sede do Departamento Estadual de Ordem Política e Social (Deops) de São Paulo, "um lugar onde se expressava uma das políticas mais truculentas do país, principalmente durante o regime militar', conforme descrição do próprio site do Memorial”, comenta a turismóloga Ana Maria Vieira Fernandes, professora das Faculdades de Turismo, Artes Visuais, Design Digital e Geografia da PUC-Campinas. Dentre os vários espaços e atividades do museu, é possível visitar as antigas celas dos presos políticos e ouvir áudios de depoimentos. "É uma forma de manter viva a história, levar conhecimento e impedir que isso volte a ocorrer", diz Fernandes.

Já o Sítio Arqueológico do Cais do Valongo, localizado na região portuária do Rio de Janeiro, foi um local de desembarque de negros africanos escravizados. Estima-se que, duran- te os vinte anos de sua operação, entre 500 mil e um milhão de negros escravizados desembarcaram no cais. O local foi reconhecido como patrimônio mundial pela Unesco em 2017. "A visitação ao local pode ser considerada um turismo de luto, pois é um conjunto de lugares de memória que nos mostra os horrores do que foi a escravidão, a desumanização dos negros africanos e as marcas que isso deixou em nossa história”, explica Fernandes.

Além desses, nos últimos anos vêm ocorrendo uma série de tombamentos e pedidos de tombamento de locais relacionados ao regime militar no Brasil, como o Destacamento de Operações de Informação - Centro de Operações de Defesa Interna (DOI-Codi, órgão de inteligência e repressão do governo) em São Paulo (SP); a Casa da Morte (nome pelo qual ficou conhecido um centro clandestino de tortura e assassinatos criado pelos órgãos de repressão da ditadura militar brasileira), em Petrópolis (RJ); e o cemitério de Perus (atualmente renomeado como Colina dos Mártires, utilizado para o sepultamento de pessoas mortas pelas forças de segurança também no período da ditadura militar), em São Paulo (SP). O mesmo processo está sendo feito com lugares relacionados à escravidão e aos hospitais-asilos (como é o caso das instituições de profilaxia da hanseníase). "Esses e muitos outros exemplos dão a certeza às pessoas que patrimônio $\mathrm{e}$ memória estão muito além de serem 'lugares ou prédios bonitos do passado' e que servem para conscientizar, repensar, evitar que esses episódios se repitam”, aponta Meneguello. 
ESQUECER OU LEMBRAR? Mas por que locais ligados a conflitos, ditadura, escravidão e mortes são importantes para o turismo? A questão é que quando esses lugares são patrimonializados pela Unesco, pelo Condephaat, ou por outro órgão, eles são reconhecidos como lugares de preservação de um episódio importante da história, que atravessa o social por meio da memória e de seus testemunhos - por mais difícil que seja lembrar - indo além de um valor puramente estético. "A visitação a esses locais pressupóe um processo de interpretação mais elaborado e não apenas mercadológico. É importante que esses lugares sejam patrimonializados por sua relevância histórica e também como símbolo de resistência. Eles estão lá como memórias vivas, para nos mostrar constantemente que não vamos esquecer, não vamos esconder, não vamos fingir que esses episódios trágicos não aconteceram. Mas vamos refletir sobre eles como parte de nossa história, e sobre todos os sentimentos que nos evocam, e aprender sobre os conflitos e sobre os sobreviventes", enfatiza o turismólogo Thiago Allis, professor da Escola de Artes, Ciências e Humanidades (EACH) da Universidade de São Paulo (USP).

Considerados lugares de memória da dor, muitas vezes visitá-los é considerado um tipo de "turismo de luto". Preservar locais como o Memorial do Genocídio em Kingali, em Ruanda, ou de Pearl Harbor (Memorial do USS Arizona, no Havaí, Estados Unidos) é melhor do que esquecê-los. "Por meio do turismo a sociedade pode conhecer mais sobre o que ocorreu no passado e compreender sua própria história e identidade. Preservar esses lugares de memória faz com que os horrores que ali aconteceram não sejam esquecidos e nunca mais voltem a acontecer. $\mathrm{O}$ turismo, portanto, é um meio de desenvolvermos a chamada 'educação patrimonial'”, afirma Fernandes, da PUC-Campinas.

ÉTICA DO TURISMo No entanto, ainda há um debate sobre se esse tipo de turismo é ético. Afinal, o que leva mais de quatro milhóes de visitantes por ano ao National 9/11 Memorial \& Museum "Ground Zero" (memorial aos atentados de 11 de setembro nos Estados Unidos), em Nova York, ou mais de um milhão de pessoas ao Museu Auschwitz-Birkenau (memorial aos campos de concentração e extermínio nazistas), em Oswiecim (Polônia)? De acordo com Allis: "se o turismo a esses locais proporcionar apenas uma espetacularização das tragédias ocorridas, ele acaba perdendo seu propósito. O turismo nesses locais de conflito, ou de memória difícil, é interessante como uma atividade crítica e reflexiva. Porque ali a obra-prima é o sofrimento de outra pessoa. Então temos que pensar sobre os agentes desses conflitos, em como aconteceram e se refletiram na vida das pessoas e se ainda refletem, porque muitos desses conflitos permanecem", aponta o professor da USP.

Nessa vertente, chamar esse turismo de "sombrio", numa tradução aproximada do inglês "dark tourism”, seria no mínimo compli- cado. "Eu acredito que o turismo sombrio é um nome muito reducionista e até estereotipado para tratar de um turismo extremamente complexo como esse", explica Allis. Isso porque esses espaços estão ligados a memórias difíceis que trazem à tona passados traumáticos, desvelando o sofrimento através do processo de patrimonialização. "Esse tipo de turismo vai além da visitação, ele exige uma reflexão e uma empatia, ele cria um elo entre o passado e o presente, repleto de sentimentos como perplexidade e solidariedade. E não dá para esvaziá-lo de seu sentido político", diz Allis.

Além disso, o termo "turismo sombrio" pode remeter ao "turismo macabro", que seria a visitação a cemitérios ou a lugares onde ocorreram crimes e assassinatos, como o Castelinho da Rua Apa, na capital paulista. "Há muitas nomenclaturas e vertentes dentro desse segmento e, por isso, acredito que o termo 'turismo de luto' seja o mais apropriado para nos referirmos aos locais onde se passaram tragédias e acontecimentos que abalaram a história da humanidade, como o holocausto, a escravidão, as ditaduras e as torturas", explica Fernandes. "Esses locais podem - e devem - ser explorados pelo turismo, pois pode ser que a partir dessa atividade tais horrores não sejam esquecidos. Quem nos contará essa história difícil? Essa é a importância desses lugares de memória, ainda que elas sejam difíceis", finaliza a professora.

Chris Bueno 